\title{
Cover illustration: Non-premixed hydrocarbon flame
}

\section{Paul E Dimotakis}

Graduate Aeronautical Laboratories, California Institute of Technology, Pasadena, CA 91125, USA

Received 27 November 1996

Recommended by R S MacKay and I Procaccia

This year's cover illustration, reproduced here as figure 1, depicts an image formed by a short-time (1/1000 s) exposure of a non-premixed hydrocarbon flame. The flow is driven by the buoyancy forces generated by the density difference from the combustion heat release and resulting temperature rise. The Reynolds number for this buoyancy-induced, turbulent flow is relatively low, estimated at a few thousand.

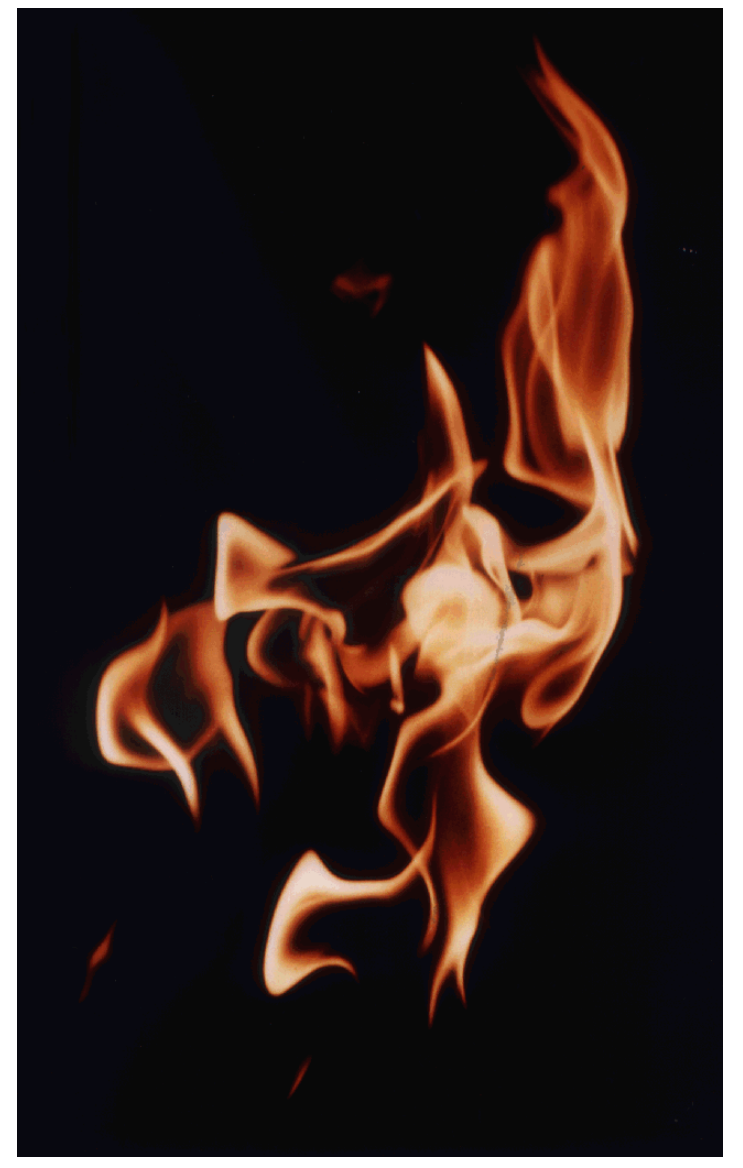

Figure 1. Non-premixed hydrocarbon flame. Reproduced by permission (c) 1971 Paul E Dimotakis. 
Combustion in non-premixed hydrocarbon flames takes place on (or very near) the unsteady, three-dimensional stoichiometric surface [1], i.e., the instantaneous surface on which the fuel-air concentration ratio is at the stoichiometric-mixture value. An image such as this relies on the light emitted from the hot, glowing soot particles generated in sheet-like regions, on the fuel-side of the burning surface, by thermal cracking of the complex hydrocarbon fuel.

Many hydrocarbon flames, both premixed and non-premixed, are characterized by unsteady burning surfaces even though, to the much slower-response (around 1/10 s) of the naked eye, they often appear as more or less solid (volume filling).

As can be seen, the 'soot-sheets' indicate a complex surface burning geometry that is not simply connected and invites the use of fractal notions for its analysis [3-6]. This has been an active area of research, some of which supports the proposal that (power-law) fractal analysis is applicable to the description of isosurfaces in turbulence [7-13], while other work suggests a scale-dependent fractal behaviour [14-19]. Extensions to the original fractal framework were recently proposed to accommodate the more general behaviour that has been observed [20-22].

\section{References}

[1] Burke S P and Schumann T E W 1928 Diffusion flames Ind. Eng. Chem. 20998

[2] Glassman I 1988 Soot formation in combustion processes 22nd International Symposium on Combustion (Pittsburgh: The Combustion Institute) 295-311

[3] Mandelbrot B B 1977 Fractals. Form, Chance, and Dimension (San Francisco: Freeman)

[4] Mandelbrot B B 1982 The Fractal Geometry of Nature (New York: Freeman)

[5] Feder J 1988 Fractals (New York: Plenum)

[6] Falconer K 1990 Fractal Geometry: Mathematical Foundations and Applications (Chichester: Wiley)

[7] Mandelbrot B B 1975 On the geometry of homogeneous turbulence, with stress on the fractal dimension of the iso-surfaces of scalars J. Fluid Mech. 72 401-16

[8] Sreenivasan K R and Meneveau C 1986 The fractal facets of turbulence J. Fluid Mech. 173 357-86

[9] Sreenivasan K R 1991 Fractals and multifractals in fluid turbulence Ann. Rev. Fluid Mech. 23 539-600

[10] Constantin P, Procaccia I and Sreenivasan K R 1991 Fractal geometry of isoscalar surfaces in turbulence: theory and experiment Phys. Rev. Lett. 67 1739-42

[11] Procaccia I, Brandenburg A, Jensen M H and Vincent A 1992 The fractal dimension of isovorticity structures in 3-dimensional turbulence Europhys. Lett. 19 183-7

[12] Constantin P 1994 Geometric statistics in turbulence SIAM Rev. 36 73-98

[13] Sreenivasan K R 1994 Fractals in fluid mechanics Fractals 2 253-63

[14] Takayasu H 1982 Differential fractal dimension of random walk and its applications to physical systems J. Phys. Soc. Japan 51 3057-64

[15] Sreenivasan K R, Prabhu A and Narasimha R 1983 Zero-crossings in turbulent signals J. Fluid Mech. 137 251-72

[16] Miller P L and Dimotakis P E 1991 Stochastic geometric properties of scalar interfaces in turbulent jets Phys. Fluids A 3 168-77

[17] Dimotakis P E 1991 Fractals, dimensional analysis and similarity, and turbulence Nonlinear Science Today (2) pp 1, 27-31

[18] Kailasnath P and Sreenivasan K R 1993 Zero crossings of velocity fluctuations in turbulent boundary layers Phys. Fluids A 5 2879-85

[19] Yee E, Chan R, Kosteniuk P R, Chandler G M, Biltoft C A and Bowers J F 1995 Measurements of levelcrossing statistics of concentration fluctuations in plumes dispersing in the atmospheric surface layer Bound. Layer. Met. 73 53-90

[20] Catrakis H J and Dimotakis P E 1996 Mixing in turbulent jets: scalar measures and isosurface geometry J. Fluid Mech. 317 369-406

[21] Dimotakis P E And Catrakis H J 1996 Turbulence, fractals, and mixing Mixing: Chaos and Turbulence (7-20 July 1996, Cargèse, Corsica, France) (NATO Advanced Studies Institute Series)

[22] Catrakis H J and Dimotakis P E 1996 Scale distributions and fractal dimensions in turbulence Phys. Rev. Lett. 77 3795-8 